\title{
Employees Perception of Training and Its Relationship with Organizational Commitment among the Employees Working at Saudi Industrial Development Fund
}

\author{
Mohammed S. Alamri ${ }^{1} \&$ Thamir I. Al-Duhaim ${ }^{2}$ \\ ${ }^{1}$ Department of Management, College of Business Administration, King Saud University, Riyadh, Saudi Arabia \\ ${ }^{2}$ College of Business Administration, Al-Yamamah University, Riyadh, Saudi Arabia \\ Correspondence: Mohammed S. Al-Amri, Associate Professor of HRM and OB, Department of Management, \\ College of Business Administration, King Saud University, Riyadh, Saudi Arabia.
}

Received: January 4, 2017

doi:10.5430/ijba.v8n2p25
Accepted: January 22, 2017

Online Published: February 24, 2017

URL: http://dx.doi.org/10.5430/ijba.v8n2p25

\begin{abstract}
The aim of this study is to examine employees perception of training provided by Saudi Industrial Development Fund (SIDF) and its relationship with organizational commitment. To achieve this aim, the study utilized a questionnaire consists of two validated, well established, international instruments: the first one is the perceived availability of training developed by Newman et al., (2011) and includes 22-item inventory that measures an individual on the training, the second instrument called commitment scale developed by Allen and Meyer, (1996) and includes 18-item inventory to identify a person's commitment. This questionnaire has been distributed to a simple random sample consist of (200) employees of Saudi Industrial Development Fund. A total of (175) complete questionnaires has been received back at a response rate of (87\%). After analyzing data and testing hypotheses, the main results of this study are:
\end{abstract}

- There is a positive relationship between five training-related variables and affective commitment.

- There is a positive relationship between two training-related variables (the perceived availability of training and perceived supervisor support for training) and two commitment-related variables (continuance and normative commitment).

- There is a negative relationship between perceived co-worker support for training and two commitment-related variables (continuance and normative commitment).

- There is no relationship between two training-related variables (the perceived benefits of training and motivation to learn) and two commitment-related variables (continuance and normative commitment).

Keywords: training, organizational commitment, affective commitment, continuance commitment, normative commitment, Saudi Industrial Development Fund, and Saudi Arabia

\section{Introduction}

In recent years, the concept of training has gained wide attention in the research literature for both managers and academicians in both public and private sector organizations. It is important to managers in general because most of the organizations treat training as their investment in the workforce. It is the process of upgrading the competencies, knowledge and attitude in performing some certain tasks. Training activity encourages the employees to think for innovative ideas for performing their tasks at the work place.

Regardless of being very expensive in nature, training and development provides worthwhile advantage in terms increase in the ability of its workforce. Training has a direct impact on productivity of the employees that ultimately translates into increase into their market worth (Goldstein and Gilliam (1990); Patrick and Bruce (2000); McNamara (2008); Afshan et al., (2012).

This enables the employee market themselves for new opportunities, which can lead to more turnover. At the same time the employees may consider an organization that provides training to their employees as a better place for working and they might refuse many opportunities and decide to stay with their parent organizations. 
Training has a vital role in developing commitment among the employees. Many researches have been focused on organizational commitment as it will be instrumental in developing loyal teams in the organization to achieve the optimum level of performance. Knowledge of organizational commitment will provide guidelines to the organization to make policies to retain the employees and enhance the commitment level of the employees. Various studies and models have been developed to study organizational commitment. In Allen and Meyer, (1991) model of organizational commitment was used with some modification.

In this study, the training is examined to investigate its relationship with organizational commitment in the Saudi Industrial Development Fund (SIDF).

\subsection{Statement of the Problem}

Training is one of the main managerial concept that have effective tools to achieve the long term goals. However, it will measure the current and future capabilities that will assure the success of the organization in this competitive world. Also training can be used to get desired outcomes that may include improved organizational commitment (Newman et al., 2011). However, the impact of training on organizational commitment has not been so widely researched. A numbers of studies have been conducted in US (Bartlett, 2001). Therefore, the problem of the study came to test the employee perception of training. It is also try to examine the relationship between training and organizational commitment among the employees working at Saudi Industrial Development Fund.

\subsection{The Purposes of the Study}

- The concept of training has been manifested to have influence in organizational commitment within the firm. This study will thereby identify or establish the reality of the relationship between training and organizational commitment among the employees of Saudi Industrial Development Fund.

- The findings of this study may contribute to more improvement in the quality of work in Saudi Industrial Development Fund.

- Due to the lack of studies in this field, the recommendations of this study may be a stimulus for researchers to focus their future researches on this vital area.

- As such, the research will be essential for the leaders in Saudi Industrial Development Fund in their policy formulations and strategic plans for their training programs and organizational commitment of employees.

\subsection{The Objectives of the Study}

- Provide an appropriate theoretical feedback that illustrates training and organizational commitment.

- Evidence indicates that training can influence work related behavior. However, there is no research which attempts to relate training and organizational commitment in Saudi Industrial Development Fund. This study considers whether there is any relationship between these two variables.

- It will fill a gap in the research literature on training and organizational commitment.

- It is also expected that the result of this study will inform the decision makers in the Saudi Industrial Development Fund about the extent of training and organizational commitment among its employees.

- It also could be of value to the Ministry of Civil Service, (the major public agency entrusted with the supervision on Saudi public organizations) to better understand human behaviors and hence be better able to make recommendations for improving productivity.

- Present proper and effective recommendations to both academicians and human resources practitioners, which will aim at creating in-depth awareness on the realities of the relationship between training and organizational commitment.

\subsection{Study Hypotheses}

The researchers divided hypotheses into three main parts:

$\mathbf{H}_{1}$ : The relationship between five training-related variables and affective commitment:

$\mathbf{H}_{1-1}$ : There is a positive relationship between the perceived availability of training and affective commitment.

$\mathbf{H}_{1-2}$ : There is a positive relationship between perceived co-worker support for training and affective commitment.

$\mathbf{H}_{\mathbf{1 - 3}}$ : There is a positive relationship between perceived supervisor support for training and affective commitment.

$\mathbf{H}_{1-4}$ : There is a positive relationship between the perceived benefits of training and affective commitment. 
$\mathbf{H}_{1-5}$ : There is a positive relationship between motivation to learn and affective commitment.

$\mathbf{H}_{\mathbf{2}}$ : The relationship between five training-related variables and continuance commitment:

$\mathbf{H}_{2-1}$ : There is a positive relationship between the perceived availability of training and continuance commitment.

$\mathbf{H}_{2-2}$ : There is a positive relationship between perceived co-worker support for training and continuance commitment.

$\mathbf{H}_{2-3}$ : There is a positive relationship between perceived supervisor support for training and continuance commitment.

$\mathbf{H}_{2-4}$ : There is a positive relationship between the perceived benefits of training and continuance commitment.

$\mathbf{H}_{2-5}$ : There is a positive relationship between motivation to learn and continuance commitment.

$\mathbf{H}_{3}$ : The relationship between five training-related variables and normative commitment:

$\mathbf{H}_{3-1}$ : There is a positive relationship between the perceived availability of training and normative commitment.

$\mathbf{H}_{3-2}$ : There is a positive relationship between perceived co-worker support for training and normative commitment.

$\mathbf{H}_{3-3}$ : There is a positive relationship between perceived supervisor support for training and normative commitment.

$\mathbf{H}_{3-4}$ : There is a positive relationship between the perceived benefits of training and normative commitment.

$\mathbf{H}_{3-5}$ : There is a positive relationship between motivation to learn and normative commitment.

\section{Theoretical Feedback and Previous Studies}

\subsection{Theoretical Feedback}

\subsubsection{Training}

Today's organizations are facing incredible pressure of various factors including economic pressure, environment pressures, legal pressures, global changes, and technological changes competition. These pressures in the organizations raise the need of a changing role of human resources. Human resources department is playing a very vital role in helping the management in achieving the strategic objectives. Colbert et al., (2007) described the new challenges and changing role of human resources as strategic partner for other functions in the organizations.

There are many examples where a company was forced to go out of business just because of poor human resources strategy. Human resources has gained rather more importance in recent years. Human resources are important to any organization because of the following reasons: training and development of the employees, keeping management focused on their job, hire right, creating policies and organizational commitment, identifying weaknesses, and improved employee performance.

Human resources become a multiplier by making managers as better managers through training and development. As a result the managers can perform better to achieve the corporate goals. Making professional managers also helps in keeping good employees in the organizations because in many organizations the employees leave because of bad managers. Human resources assist the managers by giving the professional advice to handle the difficult employees.

Training is one of the core functions of human resources. Many of the organizations have specialized department for training their employees. Training helps the organizations to keep their employees up-to-date and equip them with new techniques and technologies. Training is not only just skills enhancement functions, it also plays its role in increasing organizational commitment and lowering the turnover of employees.

Usually training affects the organization in the following ways: First, no human is perfect. Employees have their weaknesses too. Training division of an organization is considered as responsible in identifying the shortcomings in the employees and they to suggest measures to overcome them. Normally the training division conducts training need analysis for each employee to identify those gap areas where an employee need training. Training division then provides training to bridge those gaps identified at the need analysis stage. This process enhances the skills, abilities and right attitude of the employees toward their job in the organization. Second, as the employees' improve their present skills and also learn new skills and knowledge related to their work, quality and quantity of their performance increases. In today's organizations training division is supposed to train the employees on environment issue, safety practice, workplace relations with other employees apart from the skills for their jobs. Third, training functions helps the employees for developing their commitment with their work and their organization. When employees obtain training opportunity from an organization they feel that their organization is caring for them. A lot of the employees who get training from the organization feel obliged and don't plan to leave the organization. There are many who prefer to stay in the organization in the hope that their organization will organize valuable training for them. Fourth, availability of training becomes a source of motivation among the employees as they feel they their value is 
increased through the skill enhancement. Many employees feel that their organization is spending money for their skills enhancement is actually spending on them. This gives them a feeling of relation and obligation toward the organization.

Training is one of the most important activities where management takes the opportunity to expand the knowledge base of the employees working in an organization. There are many objection by management experts on providing training to the employees. Many of them consider training as administrative problem and some think it is and economic burden on the organization. Despite the criticism, training provides the organization employees with better skills and also raise the motivation level of the employees. This benefits to the organization and the employee simultaneously.

Perception of training has a very significant impact on the minds of the employee working in an organization. Ahmad and Baker (2003) suggest that if the employees have a positive perception of training they will have higher level of motivation for getting training. They also found that if the organization spends money on training it will result in stronger commitment with the organization. They also are more committed to the organization. Motivation of the employees toward training is very important in learning process. Training process depends upon the personal characteristics and the perception about how training will benefit the employee (Burke \& Hutchins, 2007). Research has focused on employees mental attitude toward training process and its outcome.

\subsubsection{Organizational Commitment}

The area of organizational commitment has been of theoretical and empirical interest by management researchers and organizational behavior scientists (Allen and Meyer, 1996; Mowday et al., 1997; Porter et al., 1974). Organizational commitment can be defined as a relationship of the employee to the organization where employee feel committed to the organization and involved emotionally in the affairs of the organization. Commitment level of the employees can vary among the employees and the organizations.

Organizational commitment is considered as psychological attachment of an employee to the organization. Normally organizational commitment is used to determine if an employee will stay with the organization or not. Organizational commitment is very popular topic in human resources now. Organizations are very much concerned about knowing about the level of commitment of an employee toward the organization. (Mathews and Jerry, 2002), defined organizational commitment as a belief interiorized by employees. (Meyer et al., 2006) also defined organizational commitment as "a force that binds an individual to a target (social or non-social) and to a course of action of relevance to that target".

Explaining organizational commitment in terms of involvement in the organization, Meyer et al., (2006) describes it as a state of being in which an individual becomes bound by actions to beliefs that sustains activities and involvement. Thompson-Hayes and Webb (2004) narrates organizational commitment as "the strength of an individual's identification with an involvement in a particular organization".

Organizational commitment is generally measured through some attributes. This attributes develop a pattern that leads to the manager to know if a particular employee or employee in general are committed to the organization. Some researchers consider commitment as a reliable linkage between employee attitudes and their work behavior because commitment is relatively a reliable behavior (Porter et al., 1974; Koch and Steers, 1978). Knowledge of commitment level is helpful for human resources management to determine the turnover rate that is helpful in planning the human resources requirements. Level of organizational commitment is identified through the responses of the employees of an organization on some selected attributes. While determining the commitment there is a difference between organizational commitment (local orientation) and professional commitment (cosmopolitan orientation). Normally if the employee is satisfied with the various attributes in an organization he is considered as committed to the organization. On the other hand if the employee is not happy with leading indicators, he will be less committed. Islam and Ismail (2008) believes that commitment is their interaction to organization. Loyalty is another level of commitment. An employee will be called as loyal if he decides to stay in the organization regardless of some level of dissatisfaction with the job or with the organization.

Allen and Mayer (1991) explain that organizational commitment is a result of multidimensional influences including three components: affective commitment, continuance commitment and normative commitment. They defined affective depends upon how much individual 'intend' to stay at his workplace, continuance commitment is covers the risks involved in leaving an organization, and normative commitment occurs when an employee feel obliged to stay in an organization as a result some goodness the employee received in the past. All these three dimensions determine the relationship of the employee with the organization. 
Commitment of the employees can be low because of the following reasons: First, human resources experts believe that recruitment stage is the most important stage in human resources process. If the employees skills are not matched rightly with the job description, it might make the employee unhappy at workplace. Second, employees perform in conductive working conditions. If the employee are not provided proper working conditions they will be unhappy and start thinking of leaving. Factors included in working conditions that raise the commitment level are the proper tools and equipment, right direction for work and opportunity to exhibit their ability and potential. Third, one of the desires an employee has in the organization is to have the opportunities to progress ahead. They expect promotions, after certain time. If the organizational structure is designed in a way that some employees don't get the opportunity for upward mobility, the employees level of commitment starts going down. Fourth, when an employee performs, he wants that his work should be recognized and he should be appreciated. Some manager individually or as a part of the culture of the organization don't recognize the outstanding performance of the employee. This lack of recognition and appreciation is also a reason for lower employee commitment with the organization. Fifth, motivation theories suggest that the employee should be reward evenly for the similar jobs. In equality in financial rewards given to the employees is among the top reasons for the low morale and low commitment of the employees in any organization. Sixth, training is among the source of motivation for employees. Many employees stay in the organization because of training opportunities available in that organization. If there will be more opportunities for the training in an organization the employees will be more committed.

Measurement of organizational commitment have many dimensions. Human resources experts and management researchers have devised a variety of ways. Lee et al., (2004) proposed studying of psychological attachment of employees to the organization. Hogg and Vaughan (2005) suggested to study compliance, identification and internationalization to know the level of commitment of the employee to the organization. Lin (2007) believes that organizational commitment should be studied through the behavior of employee toward other employees and policies of the organization.

Porter et al. (1974) considers organizational commitment as how much an individual identifies with the organization where he works. In their opinion organization commitment should be measure from three factors i.e. believing in the values of the organization, putting efforts for the organization, and desire to be attached to be identified with the organization. Steers (1977) suggested a two factor model that includes antecedents and consequences of organizational commitment. He further grouped antecedents as type of personality, nature of the job and experience of the person with the organization.

Allen and Meyer (1991) suggested to measure employee commitment by model. This model is one of the most commonly used model in the assessment of organizational commitment. They are the pioneer who argued that human behavior and human attitude toward organization and coworkers should be studied comprehensively to reach a conclusion about an employee's commitment to an organization. They suggested that the relationship of individual values of the employee and the values of the organization determines of the employee decides to stay in the organization or plan to quit from his job to join another organization. They also included three components in studying organizational commitment, they are: affective commitment, continuance commitment and normative commitment.

\subsection{Previous Studies}

Organizational commitment is catching the attention of organizational psychologists and behavior scientists. Committed employees can be a resource for any organization to achieve high productivity. Training is always considered as a source of motivation for the employees working in an organization. Availability of training, benefits of training, motivation to learn, role of coworkers and supervisors and their relationship with organizational commitment has not been a topic of researchers in the past.

In recent year this topic has attracted the attention of the researchers. There are many studies related to the topic of the current study, examples of these studies are: Mathieu and Zajac (1990) found strong correlation between personal characteristics and nature of the work in developing the organizational commitment. According to their work, to study the organizational commitment it is important to study biographic factors of the employee and work environment available in the organization. In biographic factors they include age, experience, gender, education etc. and in work environment they include nature of work, type of leadership and overall culture of the organization. Becker et al., (1996) states training can be one of the tools to raise the commitment and increase the loyalty of the employees. McNeese-Smith (2001) suggests that training opportunity was one of the most important factors in developing organizational commitment among nurses. Bartlett (2001) reported a positive correlation of access to training with organizational commitment. Ahmad and Abu Bakar (2003) found that training having relationship with organizational commitment among white-collar workers in Malysia. Al-Emadi and Marquardt (2007) found that there is a positive 
correlation between positive training perception and organizational commitment. They also found that favorable perception of the training helps the employees in social bonding with the organization. Organizations try to create positive perception of the employees for well-being of the organization as a whole. Bulut and Culha (2010) states that all the variables of training affect positively the organizational commitment. Newman et al., (2011) reported the importance of training as a tool to enhance the affective organizational commitment of employees in China. Riaz et al., (2013) confirmed a significant positive relationship between employees perception of training benefits and organizational commitment in banking sector of Pakistan. Finally, Chelliah et al., (2016) found a significant positive relationship between training components and organizational commitment. Professionally organized organizations keep an eye on the employee commitment to the organization. High level of commitment can have a very significant impact on the economy of stability of any organization. Low commitment hits even harder to small and medium organizations.

What distinguishes this study from previous studies that its deal with Saudi Industrial Development Fund (SIDF), which have not been investigated as the best of the researchers' knowledge; in addition the current study covered a number of hypotheses that have not been previously considered, at least empirically.

\section{Study's Methodology}

This study conducted descriptive and analytical study design on the relationship between training and organizational commitment among the employees working in Saudi Industrial Development Fund. Specifically, the researcher collected the necessary data and information that will use in the entire study. Primary and secondary data were used for the current study. Primary data were collected through questionnaire. Secondary data (theoretical feedback and previous studies) were collected through different sources of books, scientific journals, and the internet.

In more details, in this section the authors outline the study approach, the study process, the selection of the sample, measuring instruments, validity the tool of the study, reliability, statistical methods used, limitations of the study, and ethical considerations.

\subsection{Study Approach}

This study includes quantitative techniques. Quantitative study techniques employ collect numerical data and use statistical analysis to arrive at valuable conclusions.

\subsection{Study Process}

The researchers came in touch with participants and asked them to participate in the study after explaining the nature and the scope of the study.

\subsection{Population and Sampling Technique}

The unit analysis is individual level. The population of this study consist of all the employees working in Saudi Industrial Development Fund (SIDF). The number of employees was obtained from the human resources department of SIDF. Currently, the number of employees is (290) employees. Out of this number, a total of (175) employees were selected at random using simple random sampling to represent the employees of Saudi Industrial Development Fund.

\subsection{Measuring Instruments}

Data was collected by means of a questionnaire designed by the researchers. It consisted of forty items, which were designed according to (likert scale): (strongly disagree, disagree, don't know, agree, strongly agree), and given the weights $(1,2,3,4$, and 5). The higher the mean, indicates to higher degree of consent on the item. As the questionnaire was divided into two parts as follows:

Part One: it included a number of items that aim to measure the training from the perspective of the sample members (22 items). This item has been divided into a set of items, namely: the perceived availability of training: measured by items (1-5), perceived co-worker support for training: measured by items (6-9), perceived supervisor support for training: measured by items (10-14), the perceived benefits of training: measured by items (15-19), motivation to learn: measured by items (20-22). The (22) items taken from Newman et al., (2011) study.

Part Two: it included a number of items that aim to measure the organizational commitment from the perspective of the sample members (18 items). This item has been divided into a set of items, namely: affective commitment: measured by items (23-28), continuance commitment: measured by items (29-34), normative commitment: measured by items (35-40). The (18) items taken from Allen and Meyer (1996) study. 


\subsection{Validity the Tool of the Study}

To testify the validity of the study, a number of steps were taken: First: a number of questionnaires were distributed to a number of referees, of professors and specialists in human resources management to assess the questions for accuracy. Based on their recommendations and comments, many modifications were done; some items were deleted, new items were added and other items were rephrased until the questionnaire reached its final form. Second: the statistician reviewed the questionnaire in terms of its format, layout, and whether the type of questions were suitable for statistical analysis. Third: a pilot study with fifty participants was conducted to further ensure the validity and reliability of the questionnaire.

\subsection{Reliability}

To examine the harmony of questionnaire statements, the Cronbach's alpha coefficient was used to calculate the internal consistency of the measuring scales the Cronbach's alpha for training dimensions and commitment dimensions. The Cronbach's alpha for training dimensions is $(0.83)$. The Cronbach's alpha for commitment dimensions is (0.78). This result indicates that the reliability coefficient for all dimensions is not less than $(0.60)$. This also means that the study tool is consistent and valid for the purposes of statistical analysis and scientific research. The results are reported in Table 1.

Table 1. Cronbach's Alpha for the reliability of training and organizational commitment

\begin{tabular}{lcc}
\hline \multicolumn{1}{c}{ Variables } & No. of Items & Cronbach's Alpha \\
\hline The perceived availability of training & 5 & 0.88 \\
\hline Perceived co-worker support for training & 4 & 0.61 \\
\hline Perceived supervisor support for training & 5 & 0.88 \\
\hline The perceived benefits of training & 5 & 0.86 \\
\hline Motivation to learn & 3 & 0.59 \\
\hline The training-related variables & 22 & 0.83 \\
\hline Affective commitment & 6 & 0.72 \\
\hline Continuance commitment & 6 & 0.82 \\
\hline Normative commitment & 6 & 0.69 \\
\hline The commitment-related variables & 18 & 0.78 \\
\hline
\end{tabular}

\subsection{Statistical Methods Used}

The following statistical methods were used for statement attributes of the study sample and for examining the hypotheses of the study: frequencies, percentages, means, standard deviation, and Pearson correlation analysis.

\subsection{Limitations of the Study}

As is the case with other study studies, the design of the current study is subject to a numbers of limitations that need to be considered. First, this study is a pioneer investigation in the relationship between training and organizational commitment in Saudi Industrial Development Fund. Thus further study is needed to assess the validity of the findings in a wider context. Second, this study was applied in Riyadh city because (1) the majority of the public and private organizations are located in this city (2) constraints of time in data collection and the limitation of financial resources. It is difficult to cover the vast area of Saudi Arabia. Hence the results can only be generalized with caution. Third, because of the conservative nature of Saudi society, and because the majority of employees in Saudi Industrial Development Fund are males, female employees were not included in the study sample in this study. The sample involved males only.

\subsection{Ethical Considerations}

The present study was subject to some ethical issues. All participants reported their acceptance regarding their participation in the research. At the same time, they were free to withdraw from it at any time without any reason. Next to this, participants were informed regarding the purpose of the study, neither their names nor the name of their 
organizations will be revealed in the research. Also, they were promised that their responses will not be seen by their employers and will be used for the purpose of scientific study only.

\section{Data Analysis of Results and Discussion}

\subsection{Hypotheses Testing}

This section examines the proposed hypotheses, each of which represents some type of relationship between the main two variables of this study (training and organizational commitment). Correlation was adapted for testing the hypotheses. The correlation tells two things about the relationship between two variables: (1) whether the direction of the relationship is positive or negative or no-exist relationship (2) the magnitude of the correlation, representing the strength of relationship between the two variables.

$\mathbf{H}_{\mathbf{1}}$ : The relationship between five training-related variables and affective commitment.

$\mathbf{H}_{1-1}$ : There is a positive relationship between the perceived availability of training and affective commitment.

Table 2. Pearson correlation between the perceived availability of training and affective commitment

\begin{tabular}{ccc}
\hline The correlation coefficient & Sig. (2-tailed) & The relationship \\
\hline 0.2158 & 0.01 & Positive relationship \\
\hline
\end{tabular}

Table 2 shows that there is a positive relationship between the perceived availability of training and affective commitment at the level of $(\alpha \leq 0.01)$. In the light of the results of this hypothesis have shown that there is a positive relationships between the perceived availability of training and affective commitment of employees in the Saudi Industrial Development Fund. So the main hypothesis is accepted.

$\mathbf{H}_{1-2}$ : There is a positive relationship between perceived co-worker support for training and affective commitment.

Table 3. Pearson correlation between perceived co-worker support for training and affective commitment

\begin{tabular}{ccc}
\hline The correlation coefficient & Sig. (2-tailed) & The relationship \\
\hline 0.1618 & 0.05 & Positive relationship \\
\hline
\end{tabular}

Table 3 shows that there is a positive relationship between perceived co-worker support for training and affective commitment at the level of $(\alpha \leq 0.05)$. In the light of the results of this hypothesis have shown that there is a positive relationships between perceived co-worker support for training and affective commitment of employees in the Saudi Industrial Development Fund. So the main hypothesis is accepted.

$\mathbf{H}_{1-3}$ : There is a positive relationship between perceived supervisor support for training and affective commitment.

Table 4. Pearson correlation between perceived supervisor support for training and affective commitment

\begin{tabular}{ccc}
\hline The correlation coefficient & Sig. (2-tailed) & The relationship \\
\hline 0.3751 & 0.01 & Positive relationship \\
\hline
\end{tabular}

Table 4 shows that there is a positive relationship between perceived supervisor support for training and affective commitment at the level of $(\alpha \leq 0.01)$. In the light of the results of this hypothesis have shown that there is a positive relationships between perceived supervisor support for training and affective commitment of employees in the Saudi Industrial Development Fund. So the main hypothesis is accepted.

$\mathbf{H}_{1-4}$ : There is a positive relationship between the perceived benefits of training and affective commitment. 
Table 5. Pearson correlation between the perceived benefits of training and affective commitment

\begin{tabular}{ccc}
\hline The correlation coefficient & Sig. (2-tailed) & The relationship \\
\hline 0.3259 & 0.01 & Positive relationship \\
\hline
\end{tabular}

Table 5 shows that there is a positive relationship between the perceived benefits of training and affective commitment at the level of $(\alpha \leq 0.01)$. In the light of the results of this hypothesis have shown that there is a positive relationships between the perceived benefits of training and affective commitment of employees in the Saudi Industrial Development Fund. So the main hypothesis is accepted.

$\mathbf{H}_{1-5}:$ There is a positive relationship between motivation to learn and affective commitment.

Table 6. Pearson correlation between motivation to learn and affective commitment

\begin{tabular}{ccc}
\hline The correlation coefficient & Sig. (2-tailed) & The relationship \\
\hline 0.1575 & 0.05 & Positive relationship
\end{tabular}

Table 5 shows that there is a positive relationship between motivation to learn and affective commitment at the level of $(\alpha \leq 0.05)$. In the light of the results of this hypothesis have shown that there is a positive relationships between motivation to learn and affective commitment of employees in the Saudi Industrial Development Fund. So the main hypothesis is accepted.

$\mathbf{H}_{2}$ : The relationship between five training-related variables and continuance commitment.

$\mathbf{H}_{2-1}$ : There is a positive relationship between the perceived availability of training and continuance commitment.

Table 7. Pearson correlation between the perceived availability of training and continuance commitment

\begin{tabular}{ccc}
\hline The correlation coefficient & Sig. (2-tailed) & The relationship \\
\hline 0.2506 & 0.01 & Positive relationship \\
\hline
\end{tabular}

Table 7 shows that there is a positive relationship between the perceived availability of training and continuance commitment at the level of $(\alpha \leq 0.01)$. In the light of the results of this hypothesis have shown that there is a positive relationships between the perceived availability of training and continuance commitment of employees in the Saudi Industrial Development Fund. So the main hypothesis is accepted.

$\mathbf{H}_{2-2}$ : There is a positive relationship between perceived co-worker support for training and continuance commitment.

Table 8. Pearson correlation between perceived co-worker support for training and continuance commitment

\begin{tabular}{ccc}
\hline The correlation coefficient & Sig. (2-tailed) & The relationship \\
\hline-0.3973 & 0.01 & Negative relationship \\
\hline
\end{tabular}

Table 8 shows that there is a negative relationship between perceived co-worker support for training and continuance commitment at the level of $(\alpha \leq 0.01)$. In the light of the results of this hypothesis have shown that there is a negative relationships between perceived co-worker support for training and continuance commitment. So the main hypothesis is rejected and the alternative hypothesis is accepted which state on: there is negative relationship, statistically, at the level of $(\alpha \leq 0.01)$, between perceived co-worker support for training and continuance commitment of employees in the Saudi Industrial Development Fund.

$\mathbf{H}_{2-3}$ : There is a positive relationship between perceived supervisor support for training and continuance commitment. 
Table 9. Pearson correlation between perceived supervisor support for training and continuance commitment

\begin{tabular}{ccc}
\hline The correlation coefficient & Sig. (2-tailed) & The relationship \\
\hline 0.1681 & 0.05 & Positive relationship \\
\hline
\end{tabular}

Table 9 shows that there is a positive relationship between perceived supervisor support for training and continuous commitment at the level of $(\alpha \leq 0.05)$. In the light of the results of this hypothesis have shown that there is a positive relationships between perceived supervisor support for training and continuous commitment of employees in the Saudi Industrial Development Fund. So the main hypothesis is accepted.

$\mathbf{H}_{2-4}$ : There is a positive relationship between the perceived benefits of training and continuance commitment.

Table 10. Pearson correlation between the perceived benefits of training and continuance commitment

\begin{tabular}{ccc}
\hline The correlation coefficient & Sig. (2-tailed) & The relationship \\
\hline-0.0003 & (N. S.) & Non-existent relationship \\
\hline
\end{tabular}

Table 10 shows that there is no relationship between the perceived benefits of training and continuance commitment. In the light of the results of this hypothesis have shown that the relationship was non-exist between the perceived benefits of training and continuance commitment. So the main hypothesis is rejected and the alternative hypothesis is accepted which state on: there is no relationship, statistically, between the perceived benefits of training and continuance commitment of employees in the Saudi Industrial Development Fund.

$\mathbf{H}_{2-5}$ : There is a positive relationship between motivation to learn and continuance commitment.

Table 11. Pearson correlation between motivation to learn and continuance commitment

\begin{tabular}{ccc}
\hline The correlation coefficient & Sig. (2-tailed) & The relationship \\
\hline-0.0585 & (N. S.) & Non-existent relationship \\
\hline
\end{tabular}

Table 11 shows that there is no relationship between motivation to learn and continuance commitment. In the light of the results of this hypothesis have shown that the relationship was non-exist between motivation to learn and continuance commitment. So the main hypothesis is rejected and the alternative hypothesis is accepted which state on: there is no relationship, statistically, between motivation to learn and continuance commitment of employees in the Saudi Industrial Development Fund.

$\mathbf{H}_{3}$ : The relationship between five training-related variables and normative commitment.

$\mathbf{H}_{3-1}$ : There is a positive relationship between the perceived availability of training and normative commitment.

Table 12. Pearson correlation between the perceived availability of training and normative commitment

\begin{tabular}{ccc}
\hline The correlation coefficient & Sig. (2-tailed) & The relationship \\
\hline 0.3578 & 0.01 & Positive relationship \\
\hline
\end{tabular}

Table 12 shows that there is a positive relationship between the perceived availability of training and normative commitment at the level of $(\alpha \leq 0.01)$. In the light of the results of this hypothesis have shown that there is a positive relationships between the perceived availability of training and normative commitment of employees in the Saudi Industrial Development Fund. So the main hypothesis is accepted.

$\mathbf{H}_{3-2}$ : There is a positive relationship between perceived co-worker support for training and normative commitment. 
Table 13. Pearson correlation between perceived co-worker support for training and normative commitment

\begin{tabular}{ccc}
\hline The correlation coefficient & Sig. (2-tailed) & The relationship \\
\hline-0.3158 & 0.01 & Negative relationship \\
\hline
\end{tabular}

Table 13 shows that there is a negative relationship between perceived co-worker support for training and normative commitment at the level of $(\alpha \leq 0.01)$. In the light of the results of this hypothesis have shown that there is a negative relationships between perceived co-worker support for training and normative commitment. So the main hypothesis is rejected and the alternative hypothesis is accepted which state on: there is negative relationship, statistically, at the level of $(\alpha \leq 0.01)$, between perceived co-worker support for training and normative commitment of employees in the Saudi Industrial Development Fund.

$\mathbf{H}_{3-3}$ : There is a positive relationship between perceived supervisor support for training and normative commitment.

Table 14. Pearson correlation between perceived supervisor support for training and normative commitment

\begin{tabular}{ccc}
\hline The correlation coefficient & Sig. (2-tailed) & The relationship \\
\hline 0.2972 & 0.01 & Positive relationship \\
\hline
\end{tabular}

Table 14 shows that there is a positive relationship between perceived supervisor support for training and normative commitment at the level of $(\alpha \leq 0.01)$. In the light of the results of this hypothesis have shown that there is a positive relationships between perceived supervisor support for training and normative commitment of employees in the Saudi Industrial Development Fund. So the main hypothesis is accepted.

$\mathbf{H}_{3-4}$ : There is a positive relationship between the perceived benefits of training and normative commitment.

Table 15. Pearson correlation between the perceived benefits of training and normative commitment

\begin{tabular}{ccc}
\hline The correlation coefficient & Sig. (2-tailed) & The relationship \\
\hline 0.0575 & (N. S.) & Non-existent relationship \\
\hline
\end{tabular}

Table 15 shows that there is no relationship between the perceived benefits of training and normative commitment. In the light of the results of this hypothesis have shown that the relationship was non-exist between the perceived benefits of training and normative commitment. So the main hypothesis is rejected and the alternative hypothesis is accepted which state on: there is no relationship, statistically, between the perceived benefits of training and normative commitment of employees in the Saudi Industrial Development Fund.

$\mathbf{H}_{3-5}$ : There is a positive relationship between motivation to learn and normative commitment.

Table 16. Pearson correlation between motivation to learn and normative commitment

\begin{tabular}{ccc}
\hline The correlation coefficient & Sig. (2-tailed) & The relationship \\
\hline 0.0432 & (N. S.) & Non-existent relationship \\
\hline
\end{tabular}

Table 16 shows that there is no relationship between motivation to learn and normative commitment. In the light of the results of this hypothesis have shown that the relationship was non-exist between motivation to learn and normative commitment. So the main hypothesis is rejected and the alternative hypothesis is accepted which state on: there is no relationship, statistically, between motivation to learn and normative commitment of employees in the Saudi Industrial Development Fund. 


\subsection{Discussion}

The discussion of the main results of this study can be divided into three main parts.

First, our study found these results: (1) the two training-related variables (the perceived availability of training and the perceived supervisor support for training) having a significant and positive relationship with all three commitment-related variables: affective, continuance and normative commitment (2) there is a positive relationship between the perceived co-worker support for training and affective commitment (3) there is a positive relationship between the two training-related variables (the perceived benefits of training and motivation to learn) and affective commitment.

Our findings are consistent with the results of previous studies (Becker et al., 1996; McNeese-Smith, 2001; Bartlett, 2001; Ahmad and Abu Bakar, 2003; Bulut and Culha, 2010; Newman et al., 2011; Riaz et al., 2013; Chelliah et al., 2016). It also confirmed with the findings of the current study support the basic premise of social exchange theory as applied to the workplace. The possible explanation is the belief that the employee is engaged in social exchange theory, as (Blau, 1964a:91) defined exchange behavior to mean "voluntary actions of individual that are motivated by the returns they are expected to bring and typically do in fact bring from others".

In addition, based on the "norm of reciprocity" (Gouldner, 1960), employees who receive personal support from their leaders, are more likely to feel the need for a reciprocal exchange relationship with the organization or with the organization in general in several useful ways: (1) to seek out ways to promote the welfare of the organization (2) to reciprocate the firm's supportive orientation with voluntary contributions that benefit the firm (Organ, 1990) such as attending meetings on quality methods, and to report that they assisted others with their job duties (3) to submit suggestions for improvement.

Second, (1) there is a negative relationship between the perceived co-worker support for training and two commitment-related variables: continuance and normative commitment. Coworker support is defined as "employees' global beliefs concerning their coworkers' attitudes toward them" (Ladd \& Henry, 2000, p. 2034). Indeed, coworkers can provide desirable support that creates positive work experiences and that may lead fellow employees to a feeling of belonging and loyalty, which characterizes affective commitment (Limpanitgul et al., 2014). Contrary to expectation, our findings showed a negative relationship between coworker support and continuance commitment. This contradicts findings from other studies (Bartlett, 2001; Ahmad and Abu Bakar, 2003). The lack of a relationship could result from one possible explanation. In the Saudi work environment, the nature of work daily is completed by employee on his or her own not in group work. In this situation, the individual works have many advantages and disadvantages, one of disadvantages of working individually is lead to noncooperation between workers, which in turn, employees at Saudi Industrial Development Fund may fail to notice that support for their colleagues influence their commitment because they are expected to look after themselves but rarely anyone else.

Third, there is no relationship between two training-related variables (the perceived benefits of training and motivation to learn) and two commitment-related variables: continuance and normative commitment. Our findings are consistent with the results of previous studies (Shore and Wayne, 1993; and Newman et al., 2011). It appears that individuals' motivation to learn and participate in training have no impact towards their assessment on the costs of leaving the organization. It can be assumed that although individuals believed that training is advantageous to them, it does not necessarily mean that it will affect their perception of the cost of leaving (Ahmad and Bakar, 2003). In addition, if the employees are not able to gain some benefits from training (e.g., participation in decision making, promotion, apply the skills in situations and contexts that are very similar to those in which the training occurred) will not be more inclined to stay with the organization that provided the training programme. As for motivation to learn, this may be result of the nature of many training programmes in Saudi and other countries is not voluntary.

\section{Conclusions}

The present study investigated the relationship between employees perception of training and its relationship with organizational commitment. The study was carried out in the context of Saudi Industrial Development Fund (SIDF). This study offered a discussion of the empirical results of the present study. The main results were: there is a positive relationship between five training-related variables and affective commitment, there is a positive relationship between two training-related variables (the perceived availability of training and perceived supervisor support for training) and two commitment-related variables (continuance and normative commitment), there is a negative relationship between perceived co-worker support for training and two commitment-related variables (continuance and normative commitment), finally, there is no relationship between two training-related variables (the perceived benefits of training and motivation to learn) and two commitment-related variables (continuance and normative 
commitment). The results of this study are generally in agreement with previous studies, especially in the Arab countries. Finally, to the best of the researchers' knowledge, the present study covered a number of hypotheses that have not been previously considered, at least empirically.

\section{Recommendations}

Through this study, a number of negative results have been identified:

First: the study found a negative relationship between perceived co-worker support for training and two commitment-related variables (continuance and normative commitment). The recommendation here is the top management in Saudi Industrial Development Fund should create and implement a policy of cooperation and transfer of experience among the older employees and younger employees in the field of work. Second: another deficiency comes as a result of inappropriate regulation and legislation. No formal link between training programme and financial benefits and motivations exists. The combination of these two (benefits and motivations) has an extremely strong negatives effect on the commitment in Saudi Industrial Development Fund. However, the recommendation here is that top management in Saudi Industrial Development Fund should be aware of the importance of motivations and create a reward system of training. Finally, it is hoped that these would be useful in improving the level of training and at the same time the level of commitment subordinates.

\section{Areas for Further Study}

The findings of this study did not cover comprehensively all factors which discuss training and commitment in the Saudi Arabia work organizations. The study provides other areas for the further research including:

- Employee perception of training and its impact on organizational commitment: a public and private sector comparison in Saudi Arabia.

- Employee perception of training and its impact on organizational commitment: a male and female comparison in Saudi Arabia.

\section{References}

Afshan, S., Sobia, I., Kamran, A., \& Nasir, M. (2012). Impact of Training on Employee Performance: A Study of Telecommunication Sector in Pakistan. Interdisciplinary Journal of Contemporary Research in Business, 4(6), 646-661. Retrieved from ijcrb.webs.com

Ahmad, K.Z., \& Bakar, R.A. (2003). The Association between Training and Organizational Commitment among White Collar Workers in Malaysia. International Journal of Training and Development, 7(3), 166-185. http://dx.doi.org/10.1111/1468-2419.00179

Al-Emadi, M.A., \& Marquardt, J.M. (2007). Relationship Between Employees' Beliefs Regarding Training Benefits and Employees' Organizational Commitment in a Petroleum Company in The State of Qatar. International Journal Of Training And Development, 11(1), 49-70. http://dx.doi.org/10.1111/j.1468-2419.2007.00269.

Allen, N.J., \& Mayer, J.P. (1991). A Three Component Conceptualization of Organizational Commitment. Human Resources Management Review, 1(1), 61-89. http://dx.doi.org/10.1016/1053-4822 (91)90011-Z

Allen, N.J., \& Meyer, J.P. (1996). Affective, Continuance, and Normative Commitment to the Organization: An Examination of Construct Validity. Journal of Vocational Behavior, 49(3), 252-276. http://dx.doi.org/10.1006/jvbe.1996.0043

Bartlett, K.R. (2001). The Relationship between Training and Organizational Commitment: A Study in the Health Care Field. Human Resources Development Quarterly, 12(4), 335-361. http://dx.doi.org/10.1002/hrdq.1001

Becker, T.E., Billings, R.S., Eveleth, D.M., \& Gilbert, N.L. (1996). Foci and Bases of Employee Commitment: Implications for Job Performance. The Academy of Management Journal, 39(2), 464-482. Retrieved from http://www.jstor.org/stable/256788

Blau, P. (1964). Exchange and Power in Social Life. New York: Wiley.

Bulut, C., \& Culha, O. (2010). The Effects of Organizational Training on Organizational Commitment. International Journal of Training and Development, 14(4), 309-332. http://dx.doi.org/10.1111/j.1468-2419.2010.00360

Burke, L., \& Hutchins, H. (2007). Training Transfer: An Integrative Literature Review. Human Resources Development Review, 6(3), 263-296. http://dx.doi.org/10.1177/1534484307303035 
Chelliah, S., Bujang, T., Lew, T., \& Adriel, K. (2016). Relationship between Training Components, Work Environment and Participants Characteristics on Transfer of Training Skills and Organizational Commitment. International Business Management, 10(9), 1623-1631. http://dx.doi.org/10.3923/ibm.2016.1623.1631

Colbert, B.A., \& Elizabeth, C.K. (2007). Three Conceptions of Triple Bottom Line Business Sustainability and the Role for Human Resources Management. People and Strategy, 30(1), 21-29.

Goldstein, I., \& Gilliam, P. (1990). Training Systems Issues in the Year 2000. American Psychologist, 45, 134-43. Retrieved from http://psycnet.apa.org/doi/10.1037/0003-066X.45.2.134

Gouldner, A.W. (1960). The Norm of Reciprocity: A Preliminary Statement. American Sociological Review, 25, 161-178. Retrieved from http://www.jstor.org/stable/2092623

Hogg, M., \& Vaughan, G. (2005). Social Psychology (4th ed.). London: Prentice-Hall.

Islam, R., \& Ismail, A.Z.H. (2008). Employee Motivation: A Malaysian Perspective, International Journal of Commerce and Management, 18(4), 344-362. http://dx.doi.org/10.1108/10569210810921960

Koch, J.L., \& Richard, M.S. (1978). Job Attachment, Satisfaction and Turnover among Public Sector Employees. Journal of Vocational Behavior, 12(1), 119-128. http://dx.doi.org/10.1016/0001-8791 (78)90013-1

Ladd, D., \& Henry, R.A. (2000). Helping Coworkers and Helping the Organization: the Role of Support Perceptions, Exchange Ideology, and Conscientiousness. Journal of Applied Social Psychology, 30(10), 2028-2049. http://dx.doi.org/10.1111/j.1559-1816.2000.tb02422

Lee, T., Mitchell, T., Sablynski, C., Burton, J., \& Holtom. B/ (2004). The Effects of Job Embeddedness on Organizational Citizenship, Job Performance, Volitional Absences, and Voluntary Turnover. Academy of Management Journal, 47(5), 711-722. Retrieved from http://www.jstor.org/stable/20159613

Limpanitgul, T., Boonchoo, P., \& Photiyarach, S. (2014). Coworker Support and Organizational Commitment: A Comparative Study of Thai Employees Working in Thai and American Airlines. Journal of Hospitality and Tourism Management, 21, 100-107. http://dx.doi.org/10.1016/j.jhtm.2014.08.002

Lin, C.P. (2007). To Share or Not to Share: Modeling Tacit Knowledge Sharing, Its Mediators and Antecedents. Journal of Business Ethics, 70(4), 411-428. http://dx.doi.org/10.1007/s10551-006-9119-0

Mathews, B., \& Jerry, L. (2002). Dimensionality of Cook and Wall's (1980) British Organizational Commitment Scale Revisited. Journal of Occupational and Organizational Psychology, 75(3), 369-375. http://dx.doi.org/10.1348/096317902320369767

Mathieu, J.E., \& Zajac, D.M. (1990). A Review and Meta-Analysis of the Antecedents, Correlates, and Consequences of Organizational Commitment. Psychological Bulletin, 108(2), 171-194. http://dx.doi.org/10.1037/0033-2909.108.2.171

McNamara, C. (2008). Employee Training and Development: Reasons and Benefits. Retrieved March 16, 2009, from http://www.managementhelp.org/index.html

McNeese-Smith, D.K. (2001). A Nursing Shortage: Building Organizational Commitment among Nurses. Journal of Healthcare Management, 46(3), 173-187.

Meyer, J., Becker, T., \& Van, R. (2006). Social Identities and Commitments at Work: Toward an Integrative Model. Journal of Organizational Behaviour, 27(5), 665-683. http://dx.doi.org/10.1002/job.383

Mowday, R.T., Steers, R.M., \& Porter, L.W. (1997). The Measurement of Organizational Commitment. Journal of Vocational Behavior, 14(2), 224-247. http://dx.doi.org/10.1016/0001-8791(79)90072-1

Newman, A., Thanacoody, R., \& Hui, W. (2011). The Impact of Employee Perceptions of Training on Organizational Commitment and Turnover Intentions: A Study of Multinationals in the Chinese Service Sector. The International Journal of Human Resources Management, 22(8), 1765-1787. http://dx.doi.org/10.1080/09585192.2011.565667

Organ, D.W. (1990). The Motivational Basis of Organizational Citizenship Behavior. In B. M. Staw and L. L. Cummings (Eds.), Research in Organizational Behaviour (Vol. 12, pp. 43-72.). Greenwich, CT: JAI Press.

Patrick, J., \& Bruce, H. (2000). Training and Development. Management: Barons and Educational Series, p. 225. 
Porter, L.W., Steers, R.M., Mowday, R.T., \& Boulian, P.V. (1974). Organizational Commitment, Job Satisfaction, and Turnover among Psychiatric Technicians. Journal of Applied Psychology, 59(5), 603-609. http://dx.doi.org/10.1037/H0037335

Riaz, A., Idress, R., \& Imran, A. (2013). Employees' Belief Regarding Training Benefits and Organizational Commitment: A Case in Banking Sector of Pakistan. Middle-East Journal of Scientific Research, 16(3), 310-318. http://dx.doi.org/10.5829/idosi.mejsr.2013.16.03.11671

Shore, L.M., \& Wayne, S.J. (1993). Commitment and Employee Behavior: Comparison of Affective and Continuance Commitment with Perceived Organizational Support. Journal of Applied Psychology, 78(5), 774-780. http://dx.doi.org/10.1037/0021-9010.78.5.774

Steers, R.M. (1977). Antecedents and Outcomes of Organizational Commitment. Administrative Science Quarterly, 22(1), 46-56. http://dx.doi.org/10.2307/2391745

Thompson-Hayes, M., \& Webb, L.M. (2004). Theory in Progress: Commitment Under Construction: A Dyadic and Communicative Model of Marital Commitment. Journal of Family Communication, 4(3), 249-260. http://dx.doi.org/10.1207/s15327698jfc0403\&4_9 